\title{
Analysis of Radioactive Microparticles Emitted from the Fukushima Nuclear Plant by Using Advanced STEM Techniques
}

\author{
Taiga Okumura $^{1 *}$, Toru Hara ${ }^{2}$ and Toshihiro Kogure ${ }^{1}$ \\ 1. Department of Earth and Planetary Science, Graduate School of Science, The University of Tokyo, \\ Tokyo, Japan. \\ 2. Research Center for Structural Materials, National Institute for Materials Science, Tsukuba, Japan. \\ * Corresponding author: okumura@eps.s.u-tokyo.ac.jp
}

A significant amount of radiocesium was emitted into the environment in the Fukushima Daiichi Nuclear Power Plant (FDNPP) accident in March 2011, which caused radioactive contamination in east Japan. Most of the radiocesium is believed to have been released in a gaseous state, and transported with aerosols in the air. Besides, spherical particles of micron size, bearing radiocesium with very high specific radioactivity, were found in aerosol filters [1]. It is likely that these particles, termed radiocesium-bearing microparticles (CsMPs), were formed in the damaged reactors and released into the environment during the accident. TEM revealed that CsMPs consist substantially of silicate glass in which $\mathrm{Cl}, \mathrm{K}, \mathrm{Fe}, \mathrm{Zn}, \mathrm{Rb}$, $\mathrm{Sn}$, and $\mathrm{Cs}$ are dissolved as major constituent elements. In the present study, we report detailed characterization of CsMPs using advanced TEM/STEM techniques, which offer several important insights into the conditions inside the reactors during the accident.

The CsMPs were collected from non-woven fabric cloth laid on a vegetable field in Fukushima Prefecture. The cloth had been left exposed for $\sim 6$ months after the accident. The CsMPs were isolated from the cloth and identified using a conventional SEM-EDS analysis. The identified CsMPs were thinned until they were electron-transparent using a Hitachi FB-2100 FIB system with a micro-sampling unit. The elemental mapping and quantitative chemical analysis were performed using JEOL JEM-2800 STEM with single or double SDD detectors. EELS analysis in a STEM mode was conducted using a Gatan Enfina spectrometer attached to the STEM. High energy resolution EDS analysis was also performed using a Hitachi HD-2700 STEM with a transition edge sensor (TES) type microcalorimetry detector [2]. The energy resolution is $\sim 8 \mathrm{eV}$ for $\mathrm{Si} \mathrm{K} \alpha$.

SEM observation showed that most of the CsMPs had a spherical shape of a few microns in diameter (Fig. 1). As a result of elemental mapping with STEM, part of the constituent elements were inhomogeneously distributed in several CsMPs although all elements were homogeneously distributed in other CsMPs (Fig. 2). Each element had a tendency for inhomogeneous distributions: $\mathrm{Cs}, \mathrm{Fe}, \mathrm{Zn}$ and $\mathrm{Cl}$ showed higher concentration near the surface than the center, and $\mathrm{K}$ had an inverse distribution; Rb showed both distributions depending on CsMPs [3]. These results suggested that Cs was originally in a gaseous state and diffused inward into the silicate glass after formation of the particles. In contrast, Fe and Zn might diffuse outward in the glass where Cs was abundant because these elements are more stable in the silicate glass with a higher concentration of alkali ions. The average chemical composition estimated from the radial distribution of the elements varied depending on the CsMPs [4].

In addition to the element analysis using a normal SDD detector, high energy resolution EDS with a microcalorimetry detector reveled some trace elements in the CsMPs [4]. All the investigated CsMPs contained $\mathrm{Mn}$ and $\mathrm{Ba}$, but $\mathrm{Mg}, \mathrm{Al}, \mathrm{Mo}, \mathrm{S}, \mathrm{U}, \mathrm{Ca}, \mathrm{Te}$, and Xe were detected in part of them (Fig. 3). One reason is that some of the elements such as Mo and $\mathrm{S}$ are included in crystals inside the CsMPs. In addition, 
boron was not detected in the glass matrix of the CsMPs using EELS, indicating that most of the control rods made of $\mathrm{B} 4 \mathrm{C}$ inside the reactors might have created a eutectic alloy without vaporization [3].

The presence of submicron crystals as inclusions in the CsMPs is also an indicator of the atmosphere in which CsMPs were formed. The submicron crystals found in this study were identified as chromium spinels $\left(\left(\mathrm{Fe}^{2+}, \mathrm{Zn}\right)\left(\mathrm{Cr}, \mathrm{Fe}^{3+}\right)_{2} \mathrm{O}_{4}\right.$, Fig. 4), digenite $\left(\mathrm{Cu}_{1.8} \mathrm{~S}\right)$, acanthite $\left(\mathrm{Ag}_{2} \mathrm{~S}\right)$, molybdenite $\left(\mathrm{MoS}_{2}\right)$, and hessite $\left(\mathrm{Ag}_{2} \mathrm{Te}\right)[3,5]$. The spinels and digenite contained ferrous iron $\left(\mathrm{Fe}^{2+}\right)$ and cuprous copper $\left(\mathrm{Cu}^{+}\right)$, respectively, suggesting that the atmosphere inside the reactors was reductive to some extent.

Thus, characterization of CsMPs gave information on the damaged reactors that are difficult to access because of the high radiation fields.

References:

[1] K Adachi et al., Sci. Rep. 3, (2013), p. 2554.

[2] T Hara et al., J. Electron Microsc. 59 (2010) p. 17.

[3] T Okumura et al., Microsc. in press.

[4] T Kogure et al., Microsc. 65 (2016) p. 451.

[5] N Yamaguchi et al., Sci. Rep. 6 (2016) p. 20548.

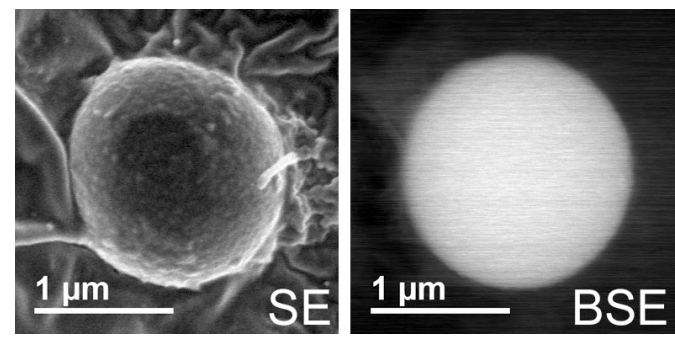

Figure 1. SEM (SE and BSE) images of a CsMP.
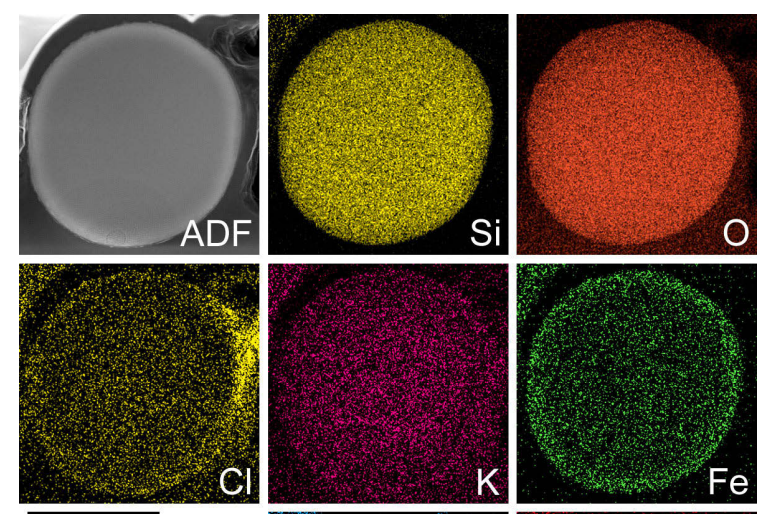

$1 \mu \mathrm{m}$
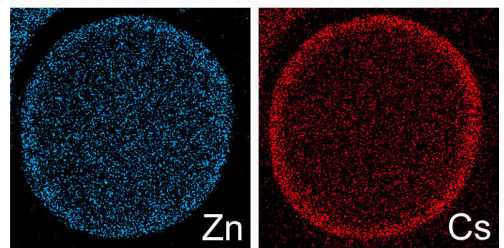

Figure 2. ADF image and corresponding elemental maps of a CsMP.

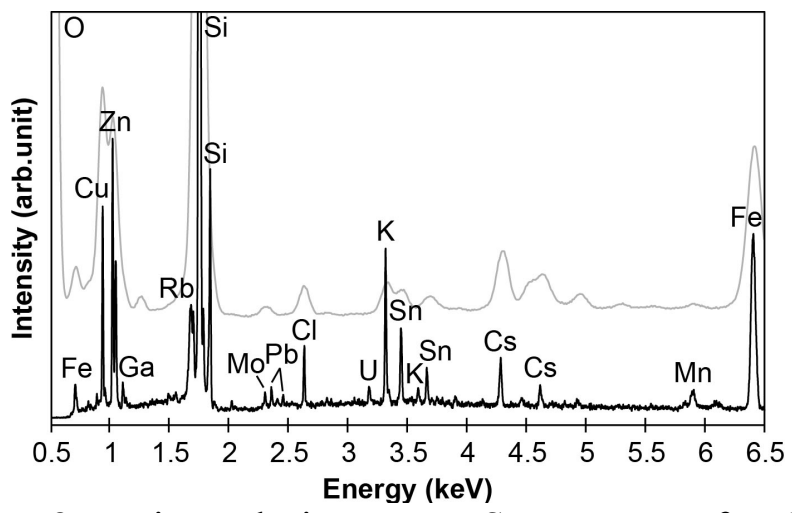

Figure 3. Microcalorimetry EDS spectrum of a CsMP (lower). The upper spectrum was obtained using a normal SDD detector (for comparison).
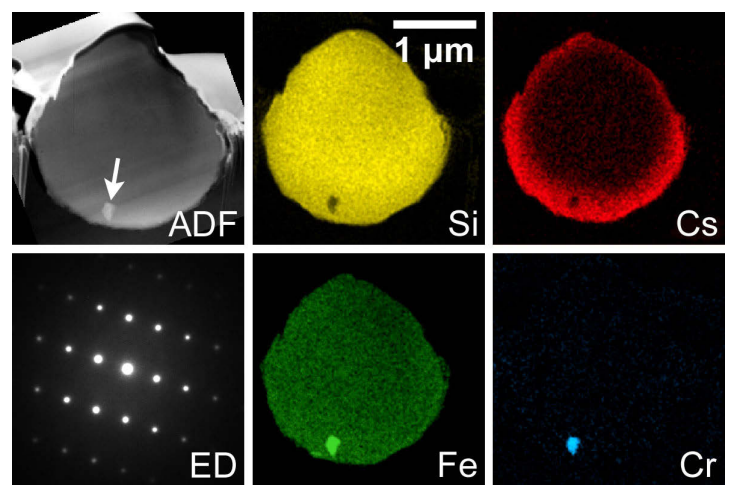

Figure 4. ADF image and corresponding elemental maps of a CsMP. Electron diffraction (ED) pattern was acquired from the spinel inclusion indicated by the white arrow. 